\title{
Low abrasive, high performing toothpastes
}

Formulated with the natural cleaning power of baking soda, Arm \& Hammer has low abrasive and high performing toothpastes for everyone.

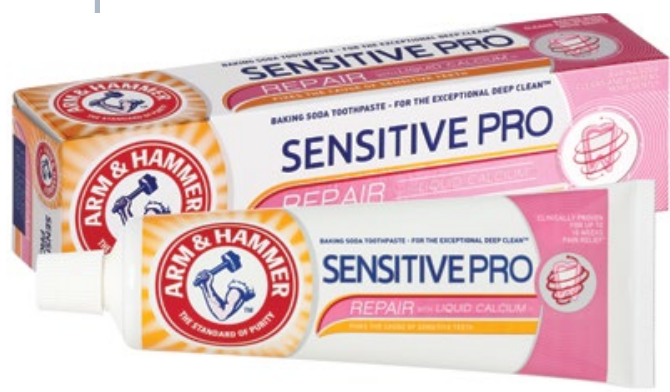

Sensitive Pro Repair toothpaste has been clinically developed to address the cause of sensitive teeth.
It is the only clinically proven toothpaste on the market that when used regularly for eight weeks, offers lasting relief from sensitivity for up to 16 weeks. It fills and repairs tooth enamel using Liquid Calcium technology and forms a shield to protect exposed nerves.

To make sensitive teeth a thing of the past, contact Arm \& Hammer now.

For more information about the carefully formulated Arm \& Hammer toothpaste range, visit http://www. armandhammer.co.uk/ or email: ukenquiries@churchdwight.com.

Arm \& Hammer oral healthcare products are available at Boots, Superdrug, Sainsbury's, Tesco, Asda and Morrisons throughout the UK.

\section{Here to support you in these difficult times}

We are all experiencing an unprecedented and unexpected challenge, both personally and professionally.

In a world of uncertainty, Patient Plan Direct would like to offer dental professionals a way forward, preparing to support you as effectively as possible once things get back on an even keel.

Over ten years ago, when Conrad Broadbent founded Patient Plan Direct, now the UK's most cost-effective major dental plan provider, no-one could have imagined the position we now find ourselves in.

However, with hundreds of happy and thriving dental practices across the UK, he goes into this challenging period with a renewed focus on bringing the most competitively priced patient plans to UK dentistry and a promise never to compromise on service.

With Patient Plan Direct, you pay only for what you NEED in a plan, not for services that you simply will never use.

In light of the current situation facing the whole business community, Patient Plan Direct has taken the decision to freeze prices and postpone the price increase that was scheduled to come into effect from April 2020.

The team hopes this will help in a small way in easing the financial pressures many currently find themselves under. This decision will be reviewed in due course, but no changes are envisaged in the foreseeable future.

With admin charges starting at $£ 1$ per patient including Global A\&E assistance, switching to Patient Plan Direct could save you up to $£ 150,000$ over five years.

For a better idea of how much your practice could save, visit the savings calculator at https://www. patientplandirect.com/savings-calculator/.

Patient Plan Direct is still able to offer a full 'business as usual' service to clients, as the business has been structured in such a way that enables the operations, support and business development teams to work seamlessly and remotely.

Patient Plan Direct believes in the metaphorical human touch. When clients call, they get through to a human being who will deal with any queries efficiently and in a timely manner, no call backs, no answerphones, no email-only contact or 'call centre mentality' at Patient Plan Direct HQ.

The team would love to hear from you, to discuss your ideas for the future and to help you fulfil your practice's full potential when we can all get back to normality.

0344848 6888, info@patientplandirect. co.uk, www.patientplandirect.com.

\section{Hard on contamination, gentle on equipment}

Choosing an appropriate medical device surface disinfectant is key to ensuring clean medical devices and avoiding cross contamination. But prolonged use of high alcohol formulas can increase the risk of deteriorating the quality of equipment and, when not used on compatible materials, may break the warranty. The highly effective low alcohol CaviWipes are tested and recommended for KaVo devices and other leading dental brands - at the same time safely protecting against bacteria, viruses, fungi and TB.

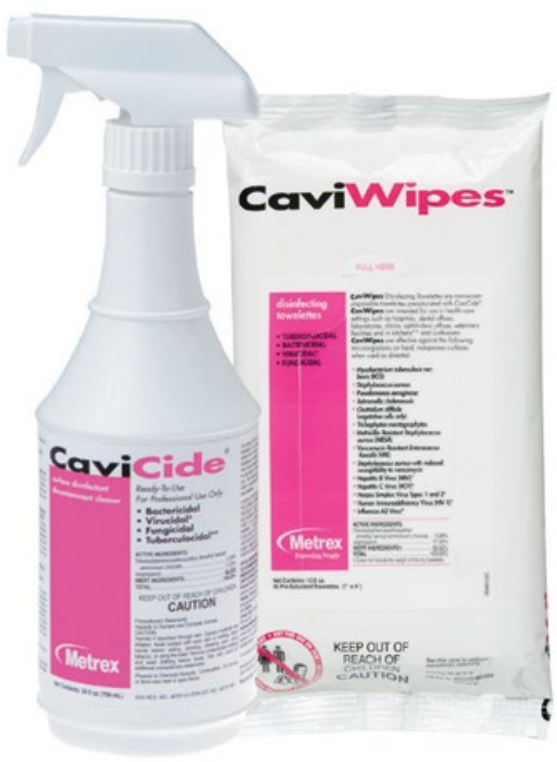

With the current pandemic its vital that you select the correct wipe to protect your team, and your patients. The European Centre for Disease Prevention and Control (ECDC) recommends the use of virucidal disinfectant products for healthcare facilities caring for patients with COVID-19. CaviWipes and CaviCide are virucidal disinfectants for use on medical equipment that meet the ECDC recommendation. CaviCide is effective against human coronavirus per ASTM E-1053-97 and CaviWipes are effective against SARSassociated coronavirus per ASTM E-1053-11.

CaviWipes are the No. 1 leading medical devices surface disinfectant wipes in the United States, boasting over ten years of proven success and US regulatory approved broad spectrum efficacy. They are trusted by leading infection control experts and used by thousands of healthcare facilities every day. 